\title{
Central Nervous System Cavernous Hemangioma
}

National Cancer Institute

\section{Source}

National Cancer Institute. Central Nervous System Cavernous Hemangioma. NCI

Thesaurus. Code C84621.

A cavernous hemangioma arising from the central nervous system. 